\title{
Analyzing Racial and Ethnic Differences in the USA through the Lens of Multidimensional Poverty
}

\author{
Shatakshee Dhongde ${ }^{1}$ (i) $\cdot$ Xiaoyu Dong $^{1}$
}

Received: 22 March 2021 / Revised: 14 December 2021 / Accepted: 15 December 2021 / Published online: 7 January 2022

(c) The Author(s), under exclusive licence to Springer Nature Switzerland AG 2022

\begin{abstract}
This paper provides a unified framework for practitioners who wish to estimate alternative indices of multidimensional poverty. These alternative indices are used to estimate multidimensional poverty in the USA over the last decade with a focus on analyzing trends by race and ethnicity. Individual level data on five different dimensions of well-being are compiled over the last decade using annual Census surveys. We find that multidimensional poverty in the USA declined over time regardless of the index used. A higher incidence of multidimensional poverty was observed among Hispanics, American Indians and Blacks. Poverty ranking among racial/ethnic groups was robust to the indices used. Estimates of alternative indices highlight different aspects of multidimensional poverty and provide complementary information on poverty in the USA in the last decade.
\end{abstract}

Keywords Multidimensional $\cdot$ Income $\cdot$ Poverty $\cdot$ Race $\cdot$ Recession $\cdot$ USA

JEL Classification D6 $\cdot \mathrm{I} 32 \cdot \mathrm{O} 51$

\section{Introduction}

In 2015, member countries of the United Nations General Assembly ratified the Sustainable Development Goals (SDGs) that succeeded the Millennium Development Goals, with the consensus of making transformative strides toward a future of shared progress within and across countries. Reducing poverty in all its dimensions is the first of the 17 SDGs and it emphasizes the need to think of poverty in a multidimensional way. Several countries in the European Union, Latin America, Africa and Asia have consistently estimated multidimensional poverty. ${ }^{1}$ Compared to other countries, the USA has lagged behind in measuring multidimensional poverty. Dhongde and Haveman (2017) were the first to provide multidimensional poverty estimates in the USA during the Great Recession. They estimated that nearly

${ }_{1}^{1}$ For a review of national reports on MPI, see https://ophi.org.uk/ publications/national-mpi-reports/

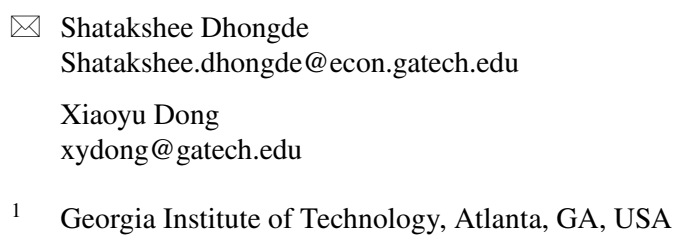

$15 \%$ of individuals were multidimensionally poor at the peak of the Great Recession. Since then, several studies have used different datasets and/or indicators to estimate changes in multidimensional poverty in the USA over time. ${ }^{2} \mathrm{~A}$ common feature in most of the recent studies in the USA is that they estimate multidimensional poverty indices proposed by Alkire and Foster (2011; AF for short). ${ }^{3}$ In this paper, for the first time, we estimate multidimensional poverty in the USA by using three alternative indices in addition to the AF indices. These alternative indices provide complementary information on multidimensional poverty and its trends in the USA in the last decade. In particular, we analyze trends in multidimensional poverty among individuals belonging to different racial and ethnic groups and test whether the ranking of these groups by multidimensional poverty varied across alternative indices.

In their seminal work, Alkire and Foster (2011) proposed multidimensional equivalence of the Foster et al. (1984)

\footnotetext{
${ }^{2}$ See for example, see Dhongde (2020), White (2020), Dhongde et al. (2019), Glassman (2019), Mitra and Brucker (2019) for estimates of poverty over multiple years since the recession.

${ }^{3}$ Except for Dhongde et al. (2019) who proposed new multidimensional well-being and deprivation indices.
} 
poverty indices. The AF indices have been widely used largely because these indices are easy to interpret and are highly intuitive. ${ }^{4}$ However, the indices have certain limitations; for instance, the AF indices do not provide any information on whether a decrease in poverty affects the poorest of the poor (Berenger, 2019). There has been a rapid growth in the literature proposing alternative axiomatic indices, few of which have been used in empirical applications. ${ }^{5}$ In this paper, we choose three alternative indices, which were proposed since the AF indices and provide improvements to the AF indices. We estimate multidimensional poverty using indices proposed by Silber and Yalonetzky (2013), Dhongde et al. (2016) and Rippin (2016). All three indices are based on an axiomatic framework, use the counting approach and can be estimated using binary data on attributes. Unlike the AF indices, these alternative indices are sensitive to inequality in the distribution of multidimensional poverty.

We estimate multidimensional poverty in the USA over the last decade (2009-2018) using data from the Census Bureau's Current Population Survey (CPS). The CPS is used to estimate the official poverty measure (OPM) in the USA. In addition to the OPM, there is also an alternative supplemental poverty measure (SPM), which is published annually and which overcomes some of the drawbacks of the OPM (Garner and Gudrais 2018). Both the OPM and the SPM are income based poverty measures. However, it has been long argued that income is an inadequate indicator of well-being and cannot fully capture an individual's capabilities (Sen 2006). In addition to income, we compile individual level data on other dimensions of well-being, such as health, employment and schooling to estimate the alternative multidimensional poverty indices proposed by Silber and Yalonetzky (2013), Dhongde et al. (2016) and Rippin (2016). We find that multidimensional poverty in the USA declined over the last decade and that the result is robust across different indices. The headcount ratio of multidimensional poverty dropped from 16 to $10 \%$, with a peak in 2010 during the Great Recession.

The widespread protests in the summer of 2020 in the USA against systemic racial injustice have brought to the forefront issues related to economic hardships among different racial/ethnic groups. Previous studies in the USA have estimated multidimensional poverty by race/ethnicity along with other population groups by gender, age, education and so on (e.g., Dhongde and Haveman 2017; Glassman 2019;

\footnotetext{
${ }^{4}$ For example, the United Nations Multidimensional Poverty Index is based on the Alkire and Foster (2011) index.

${ }^{5}$ For a review, see Pattanaik and Xu (2018), Dotter and Klasen (2017), and Aaberge and Brandolini (2015).
}

Mitra and Brucker 2019). Instead, in this paper, we focus primarily on measuring multidimensional poverty among different racial/ethnic groups which are defined within the Census. We analyze how deprivation in each of the dimensions varied among individuals belonging to these racial/ ethnic groups. More than $30 \%$ of Hispanics and American Indians had no health insurance. Few studies have estimated multidimensional poverty among American Indians. We find that compared with other groups, American Indians had a lower decline in unemployment rates during the recovery following the Great Recession. The ranking of racial/ethnic groups in terms of multidimensional poverty is consistent across all alternative indices. We also decompose poverty indices and estimate the contribution of each of the racial and ethnic group to overall poverty. We find that Hispanics had the largest share in multidimensional poverty, followed by American Indians, Blacks and Asians.

The remainder of the paper is designed as follows. In "Basic Framework of Multidimensional Poverty Indices" section, we provide a basic framework for measuring multidimensional poverty indices. In "Alternative Multidimensional Poverty Indices" section, we discuss the different indices of multidimensional poverty and provide numerical illustrations for each of these indices. Details about the data and trends in deprivation in each of the attributes are discussed in "Data and Attributes" section. In "The Headcount ratio of Multidimensional Poverty" section, we estimate the headcount ratio of multidimensional poverty for the overall population and among population groups by race/ethnicity. "Alternative Indices of Multidimensional Poverty" section contains estimates of alternative indices of multidimensional poverty. We decompose poverty indices by racial and ethnic groups. Finally, "Conclusion" section concludes by summarizing the main findings of the paper and pointing to some of the limitations and future directions for research.

\section{Basic Framework of Multidimensional Poverty Indices}

Formulating a multidimensional poverty index typically involves three steps: i) specification of well-being attributes and, for each attribute, choosing a weight and a threshold, ii) identification of individuals who are included in the set of multidimensional poor and iii) aggregation which involves summarizing individual deprivations into an overall poverty index.

\section{Specification}

Assume there are $n \geq 2$ individuals in a society, and let $N=\{1,2 \ldots n\}$. Let $k \geq 2$ be the attributes indexed by $K=\{1,2 \ldots k\}$, and let $a_{j}>0$ be the weight assigned to 
attribute $j$, such that $\sum_{j=1}^{k} a_{j}=1$. For each individual $i$, her achievement in attribute $j$ is given by $x_{i j}$ and $x_{i}=\left(x_{i 1}, x_{i 2} \ldots x_{i k}\right)$ is individual $i$ 's achievement vector. The achievement matrix of the society can be represented as $\boldsymbol{X} \in R_{+}^{N K}$. An individual's achievement in attribute $j$ is compared with a threshold value $z_{j}$ and the threshold vector is denoted by $z=\left(z_{1}, z_{2} \ldots z_{k}\right)$. Individual $i$ is deprived in attribute $j$ if $x_{i j}<z_{j}$. Furthermore, individual $i^{\prime} s$ deprivation in each attribute is summarized in a deprivation vector, $c_{i}=\left(c_{i 1}, c_{i 2} \ldots c_{i k}\right)$, where $c_{i j}=1$ if $x_{i j}<z_{j}$, and $c_{i j}=0$ if $x_{i j} \geq z_{j}{ }^{6} \boldsymbol{C}$ is the deprivation matrix of the society. Let $\delta_{i}=\sum_{j \in\{1, \ldots k\}: c_{i j=1}} a_{j}$ denote the sum of weighted deprivations experienced by individual $i$ and $\delta$ be the vector of weighted deprivation scores of all individuals.

$$
\begin{gathered}
\text { Illustrative Example } \\
\text { Achievement Matrix } \\
\quad(\mathrm{n}=4 ; \mathrm{k}=5) \\
\boldsymbol{X}=\left[\begin{array}{rrrrr}
6 & 2 & 100.3 & 15.8 & 0 \\
5 & 5 & 400.1 & 19.2 & 1 \\
9 & 4 & 200.8 & 17.4 & 1 \\
7 & 3 & 103.2 & 11.1 & 0
\end{array}\right] \quad \boldsymbol{C}=
\end{gathered}
$$

Consider an illustrative example with 4 individuals and 5 attributes. Given a threshold for each attribute, the society's achievement matrix $\boldsymbol{X}$ is transformed into a social deprivation matrix $\boldsymbol{C}$ using the attribute threshold vector $z$. For individual 4 , for example, deprivation in each attribute is summarized by, $c_{4}=(1,0,0,1,1)$. Assuming equal weights $a_{j}=1 / 5$ for each attribute, the sum of weighted deprivations for individual 4 , is $\delta_{4}=3 / 5$.

\section{Identification}

The social deprivation matrix $\boldsymbol{C}$ summarizes deprivation experienced by each individual in each of the multiple attributes. A next step is to identify which of these individuals will be considered multidimensional poor. Let $q \leq n$ denote the number of multidimensional poor. Let $N^{*} \subseteq N$ denote the set of individuals who are identified as multidimensional poor. Broadly, there are three approaches used when identifying the multidimensional poor:

1) The Union Approach This approach identifies individuals as multidimensional poor if they are deprived in at least one attribute. In the illustrative example, $N^{*}=\{1,2,4\}$ since these individuals are deprived in at least one attribute.

\footnotetext{
${ }^{6}$ Note that this specification implies the application of the strong focus axiom (Bourguignon and Chakravarty 2003), which states that the poverty measure is insensitive to the increase in achievement above the threshold.
}

2) The Intersection Approach This approach identifies individuals as multidimensional poor if and only if they are deprived in each and every attribute. In the example, $N^{*}=\{1\}$, since only individual 1 is deprived in each of the five attributes. Both the union and the intersection method are detailed in Atkinson (2003).

3) The Intermediate Approach As the name suggests, this approach is in between the union method and intersection method. Recall that $\delta_{i}=\sum_{j \in\{1, \ldots k\}: c_{i j=1}} a_{j}$ denotes the sum of weighted deprivations experienced by individual $i$. Let $\delta^{\min } \in[0,1]$ denote some minimum level of weighted deprivation. In the intermediate approach, individuals whose weighted deprivation score is at least as high as this threshold $\left(\delta_{i} \geq \delta^{\mathrm{min}}\right)$ are identified as multidimensional poor. In the previous example, if we set $\delta^{\min }=2 / 5$ then $N^{*}=\{1,4\}$. Note that the union and intersection approaches are two special cases of the intermediate approach, where $\delta^{\min }=\min \left\{a_{1}, \ldots, a_{k}\right\}$ and $\delta^{\min }=1$, respectively.

The union method assumes that all attributes are complements so that deprivation in any one attribute equals deprivation in all attributes; the intersection method assumes that all attributes are perfect substitutes since a loss in any attribute can always be completely compensated through attainment in other attributes, unless a person is deprived in all attributes; and the intermediate method is based on the assumption that up to the minimum level, attributes are perfect substitutes, whereas the same attributes are considered perfect complements from the minimum level onwards.

\section{Aggregation}

Once individuals are identified as multidimensional poor, a next step is to aggregate individual deprivations into a composite index. There are two distinct aggregation methods: column-first and row-first (see Pattanaik and Xu 2018; Berenger 2019). The column-first method of aggregation is typically used when data on attributes are compiled from different sources. In this method, we first aggregate all individuals' deprivation in each attribute (a column in the social deprivation matrix) and then aggregate these attribute-specific sums in an index. The row-first method aggregates each individual's deprivation vector (a row in the social deprivation matrix) and then aggregates individual deprivation scores into an overall deprivation index. The row-first method is data-intensive; it requires the same dataset to have information on all individuals and all attributes, but it captures the overlapping deprivations simultaneously experienced by an individual. We consider indices which follow the row-first aggregation method. 


\section{Alternative Multidimensional Poverty Indices}

\section{The Alkire and Foster (2011) Index}

The AF index is simple and easy to interpret, and has been widely used to measure multidimensional poverty across countries. ${ }^{7}$ The AF index uses the intermediate approach for identification of multidimensional poor. Thus, individuals whose deprivation scores are at least as high as some threshold are identified as multidimensional poor $N^{*}=\left(i \in N: \delta_{i} \geq \delta^{\min }\right)$. The adjusted headcount ratio $\left(P_{A F}\right)$ is denoted in Eq. (1).

$P_{A F}(\mathbf{X} ; \mathbf{z})=\frac{1}{n} \sum_{i \in N^{*}} \delta_{i}$

In the illustrative example, $\delta=\left(\frac{5}{5}, \frac{1}{5}, \frac{0}{5}, \frac{3}{5}\right)$. If we set the threshold, $\delta^{\min }=\frac{2}{5}$, then $N^{*}=\{1,4\}$. Then using Eq. (1), we know that $P_{A F}=\frac{1}{4}\left(\frac{5}{5}+\frac{3}{5}\right)=\frac{2}{5}$. The index shows the actual number of deprivations among the multidimensional poor (8) as a share of the maximum number of deprivations $(5 \times 4=20)$ possible in the society. Equation (2) shows that the adjusted headcount ratio $\left(P_{A F}\right)$ can also be expressed as a product of the headcount ratio $\left(H=\frac{q}{n}=\frac{2}{4}\right)$, which gives the proportion of multidimensional poor and the average intensity index $\left(A=\frac{1}{q} \sum_{i \in N^{*}} \delta_{i}=\frac{1}{2}\left(\frac{5}{5}+\frac{3}{5}\right)=\frac{4}{5}\right)$, which give the average deprivation share among the multidimensional poor.

$P_{A F}(\mathbf{X} ; \mathbf{z})=\frac{q}{n} x \frac{1}{q} \sum_{i \in N^{*}} \delta_{i}=H x A$

We summarize the axiomatic properties alternative indices in Appendix Table 6. The $P_{A F}$ index satisfies important properties such as decomposability and dimensional monotonicity. However, there are drawbacks underlying the adjusted headcount index. Since the index uses the intermediate identification approach, it implicitly assumes attributes to be perfect substitutes as long as the deprivation score is less than the threshold, $\left(\delta_{i}<\delta^{\text {min }}\right)$ and to be perfect complements thereafter. Additionally, the index is insensitive to inequality among the poor and does not tell us whether or not deprivation is evenly distributed among the poor. The other three indices, which follow, improve upon the AF indices by including information on the distribution of deprivation scores among the multidimensional poor.

\footnotetext{
7 For example, see Battiston et al. (2013) for 6 Latin American countries; Whelan et al. (2014) for 28 European countries; Alkire and Seth (2015) for India; Santos and Villatoro (2018) for 17 countries in Latin America; Aguilar and Sumner (2020) for global poverty.
}

\section{Silber and Yalonetzky (2013) Index}

Silber and Yalonetzky (2013) identified multidimensional poor by using a social poverty function. The social poverty function is a probability function, $S(d)=\operatorname{Pr}\left(\left(\sum_{j=1}^{k} c_{i j}\right) \geq d\right)$, where $d \in[0, k]$ and $\mathrm{k}$ is the maximal number of deprivations. Therefore, this probability represents the extent to which people are suffering from deprivation given a specific threshold $d$. The social poverty function is calculated by varying the threshold values. Let $m$ be a positive integer, $m \in[1, k]$ and assume equal weights to all attributes $\left(a_{j}=1 / k\right){ }^{8}$ The Silber and Yalonetzky (2013) index $\left(P_{S Y}\right)$ can be expressed as:

$P_{S Y}(\mathbf{X} ; \mathbf{z})=\frac{1}{k-m+1} \sum_{d=m}^{k} \mathrm{~g}[S(d)]$

In Eq. (3), $g($.$) is a nonnegative, non-decreasing real-$ valued function taking the values $\mathrm{g}(0)=0$ and $\mathrm{g}(1)=1$ and $\mathrm{g}^{\prime}>=0$ and $\mathrm{g}^{\prime \prime}<0$. Unlike $P_{A F}$, the index $P_{S Y}$ is not decomposable by attributes or subgroups. However, similar to $P_{A F}$, it can be estimated using the union or the intersection approach to identification.

In the illustrative example, we have five attributes; hence, $\mathrm{k}=5$ and $m$ can vary from 1 to 5 . When $\mathrm{m}=1$, we have a union approach and the social poverty function calculates the probability that individuals will have at least one deprivation. On the other hand, when $m=5$, then we have an intermediate approach and the social poverty function calculates the probability of individuals having deprivation in all 5 attributes. Consider $g[S]=2 S-S^{2}$ and $m=2$. Recall that in the illustrative example in "Specification" section, there are 4 individuals who are deprived in 5, 1, 0 and 3 attributes, respectively. Therefore, when $d=m=2$, we have $S(2)=\operatorname{Pr}\left(\left(\sum_{j=1}^{k} c_{i j}\right) \geq 2\right)=\frac{2}{4}$, which indicates that $N^{*}=\{1,4\}$ have been identified as deprived, and accordingly, $\mathrm{g}[S(2)]=2 \mathrm{~S}-\mathrm{S}^{2}=2 x_{\frac{2}{4}}-\left(\frac{2}{4}\right)^{2}=\frac{12}{16}$. Similarly, for $S(3)=\frac{2}{4}, g[S(3)]=\frac{12}{16}$ and $S(4)=S(5)=\frac{1}{4}, g[S(4)]=g[S(5)]=\frac{7}{16} \quad 7 \quad$. $\mathrm{Th} P_{S Y}(\mathbf{X} ; \mathbf{z})=\frac{1}{4} \sum_{d=2}^{5} \mathrm{~g}[S(d)]=\frac{1}{4}\left\{\frac{12}{16}+\frac{12^{16}}{16}+\frac{7}{16}+\frac{7}{16}\right\}=\frac{38}{64}$

\section{Dhongde et al. (2016) Index}

Dhongde et al. (2016) and Rippin (2016) simplified the identification step by utilizing the union approach instead of the intermediate approach. Thus, individuals who are deprived in at least one attribute are identified as multidimensional

\footnotetext{
${ }^{8}$ See Berenger (2017) who proposes a modified Silber and Yalonetzky (2013) measure which allows for a more general weighting
} schemes. 
poor $N^{*}=\left(i \in N: \delta_{i} \geq \min \left\{a_{1}, \ldots, a_{k}\right\}\right)$. In the illustrative example, we had $N^{*}=\{1,2,4\}$ since $\delta=\left(\frac{5}{5}, \frac{1}{5}, \frac{0}{5}, \frac{3}{5}\right)$. Both these indices take into account the distribution of deprivations among individuals and are sensitive to changes in this distribution. We start with Dhongde et al. (2016) since it provides a more general framework. Dhongde et al. (2016) refer to the weighted deprivation score, $\delta_{i}=\sum_{j=1}^{k} a_{j}$ as an individual's nominal deprivation, and introduce an individual's real deprivation, $g\left(\delta_{i}\right)$, which is an increasing and convex function in terms of the number of deprivations experienced by an individual $g:[0,1] \rightarrow[0,1]$ with $g(0)=0$, $g(1)=1$, and $g^{\prime}>0$ and $g^{\prime \prime}>0$. Then a general aggregated social deprivation can be expressed as shown in Eq. (4).

$P_{D O}(\mathbf{X} ; \mathbf{z})=\frac{1}{n} \sum_{i \in N^{*}} g\left(\delta_{i}\right)$

Thus, everything else remaining constant, if deprivations are more concentrated and less equally distributed, then the index will increase. ${ }^{9}$ Suppose $\mathrm{g}($.$) is a power function$ $(t)=t^{\beta}$; if $\beta>1$, then it is increasing and convex; let $\beta=2$. Recall that in the illustrative example, $\delta=\left(\frac{5}{5}, \frac{1}{5}, \frac{0}{5}, \frac{3}{5}\right)$; thus, we can identify individuals $N^{*}=\{1,2,4\}$ as multidimensional poor by using the union method. Then $P_{D O}(\mathbf{X} ; \mathbf{z})=\frac{1}{n} \sum_{i=1}^{n}\left(\delta_{i}\right)^{2}=\frac{1}{4}\left(1+\frac{1}{25}+0+\frac{9}{25}\right)=\frac{35}{100}$.

\section{Rippin (2016)Index}

Rippin (2016) index can be treated as a special case of the more general index proposed by Dhongde et al. (2016). This index also uses the union approach $N^{*}=\left(i \in N: \delta_{i} \geq \min \left\{a_{1}, \ldots, a_{k}\right\}\right)$ to identify multidimensional poor, similar to the approach adopted by Dhongde et al. (2016). Equation (5) shows the index $\left(P_{R P}\right)$ which is also referred to as the correlation-sensitive deprivation index:

$P_{R P}(\mathbf{X} ; \mathbf{z})=\frac{1}{n} \sum_{i \in N^{*}}\left(\delta_{i}\right)^{\alpha} \sum_{i \in N^{*}} a_{j}=\frac{1}{n} \sum_{i \in N^{*}}\left(\delta_{i}\right)^{\alpha+1}$

Similar to $P_{D O}, P_{R P}$ is non-decreasing in the number of deprived attributes. Rippin (2016) discusses in detail how the relationship among attributes depends on the value of $\alpha$ which is also referred to as a parameter of aversion to interpersonal inequality. When $\alpha>1$, then an increase in the level of poverty severity is marginally increasing in the number of deprivations. Thus, attributes are substitutes and achievement in an attribute can compensate for the loss in another attribute. When $\alpha=1$, it means inequality aversion

\footnotetext{
9 Dhongde et al. (2016) call this property as the DeprivationDecreasing Switch (DDS).
}

is linearly increasing in the number of deprivations, and the attributes are independent of each other. Finally, when $\alpha<1$, an increase in the level of poverty severity is marginally decreasing in the number of deprivations, since the loss in even one attribute can hardly be compensated; thus, attributes are complements of each other.

The index $P_{R P}$ can be decomposed similar to $P_{A F}$ and expressed as a product of: i) $H=\frac{q}{n}$ i.e. the incidence of poverty, ii) the average intensity index $A=\frac{1}{q} \sum_{i \in N} \delta_{i}$ and iii) a Ge neralized Entropy index $G E_{\alpha+1}=\frac{1}{q\left(\alpha^{2}+\alpha\right)} \sum_{i=1}^{q}\left[\left(\frac{\delta_{i}}{A}\right)^{\alpha+1}-1\right]$ which evaluates the inequality of the distribution of deprivations among the poor. We show this decomposition in Eq. (6).

$P_{R P}(\mathbf{X} ; \mathbf{z})=H x(A)^{\alpha+1} x\left\{1+\left[(\alpha+1)^{2}-(\alpha+1)\right] G E_{\alpha+1}\left(x_{i j} ; z\right)\right\}$

In our example, where $\delta=\left(\frac{5}{5}, \frac{1}{5}, \frac{0}{5}, \frac{3}{5}\right)$, suppose we assume attributes are substitutes and $\alpha=1.5$ as in Berenger (2019).

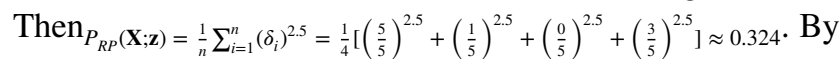
using the union method, we can identify individuals $N^{*}=\{1,2,4\}$ as multidimensional poor. Then we get $H=\frac{3}{4}$ as the headcount ratio, $A=\frac{1}{3}\left(\frac{5}{5}+\frac{1}{5}+0+\frac{3}{5}\right)=\frac{3}{5}$ as the average intensity index and $G E_{\alpha+1}=\frac{1}{q\left(\alpha^{2}+\alpha\right)} \sum_{i=1}^{q}\left[\left(\frac{\sigma_{i}}{A}\right)^{\alpha+1}-1\right]$ $=\left[\frac{1}{\left.3 *(1.5)^{2}+1.5\right)}\right]\left[\left(\frac{1}{3 / 5}\right)^{2.5}-1+\left(\frac{1 / 5}{3 / 5}\right)^{2.5}-1+\left(\frac{3 / 5}{3 / 5}\right)^{2.5}-1\right] \approx 0.1467$ as the genera $1 \mathrm{i} \mathrm{zed} \quad$ e n t r o p y i n d e x . Thus, $P_{R P}(\mathrm{X} ; \mathrm{z})=\frac{3}{4} \times\left(\frac{3}{5}\right)^{2.5} x\left\{1+\left[(2.5)^{2}-2.5\right] \times 0.1467\right\} \approx 0.324$, which arrives at the same value as when using Eq. (5).

Table 1 provides a brief summary of all the four indices including their functional forms and important features. The $P_{A F}$ index uses a two-step identification process to measure multidimensional poverty. The first threshold is defined for each of the attributes; the second threshold specifies the number of simultaneously experienced deprivations that will lead to the identification of the individual as multidimensional poor. Thus, the identification in this index is flexible and can be chosen according to the context in which the index is used. On the other hand, other indices, such as $P_{S Y}, P_{D O}$ and $P_{R P}$ use the union approach for identification but put a greater emphasis on the aggregation of deprivations by taking into account the distribution of deprivation counts (Berenger 2019). These measures capture the inequality in the distribution of deprivation by assigning higher weights to individuals with more deprivations. In the following sections, we estimate each of these indices over the 10-year period for the overall population and separately for population subgroups by race and ethnicity. 
Table 1 Summary of Alternative Multidimensional Poverty Indices

\begin{tabular}{lll}
\hline Studies & Index Estimated & Important Features \\
\hline Alkire and Foster (2011) & $P_{A F}(\mathbf{X} ; \mathbf{z})=\frac{1}{n} \sum_{i \in N^{*}} \delta_{i}$ & $\begin{array}{c}\text { Decomposable by subgroups, attributes. } \\
\text { Expressed as product of two indices }\end{array}$ \\
Silber and Yalonetzky (2013) & $P_{S Y}(\mathbf{X} ; \mathbf{z})=\frac{1}{k-m+1} \sum_{d=m}^{k}\left[2 S(d)-(S(d))^{2}\right]$ & Probability in terms of the number of deprivations \\
Dhongde et al. (2016) & $P_{D O}(\mathbf{X} ; \mathbf{z})=\frac{1}{n} \sum_{i \in N^{*}} \delta_{i}^{2}$ & $\begin{array}{c}\text { Satisfies deprivation decreasing switch } \\
\text { Rippin (2016) }\end{array}$ \\
& $P_{R P}(\mathbf{X} ; \mathbf{z})=\frac{1}{n} \sum_{i \in N^{*}}\left(\delta_{i}\right)^{2.5}$ & $\begin{array}{c}\text { Decomposable by subgroups and attributes. } \\
\text { Expressed as product of two indices }\end{array}$ \\
& & Inequality aversion
\end{tabular}

Table 2 Multidimensional Poverty Dimensions, Attributes and Thresholds

\begin{tabular}{|c|c|c|}
\hline Dimensions & Attributes & Threshold: Deprived if... \\
\hline 1. Health & $\begin{array}{l}\text { Self-evaluated Health Status } \\
\text { Multiple Disabilities }\end{array}$ & $\begin{array}{l}\text { Self-report health is poor, or has } 2 \text { or } \\
\text { more disabilities }\end{array}$ \\
\hline 2. Education & High school education & Less than high school education \\
\hline 3. Std. Of Living & Income & Income below SPM poverty threshold \\
\hline 4. Personal Activities & Employment Status & Unemployed \\
\hline 5. Economic Security & Health Insurance & No health insurance, private or public \\
\hline
\end{tabular}

\section{Data and Attributes}

\section{Data}

We use data between 2009 and 2018 from the Annual Social and Economic (ASEC) March Supplement of the Current Population Survey (CPS). Previous studies have mostly relied on the American Community Survey (ACS) to measure multidimensional poverty in the USA. ${ }^{10}$ Although the ACS has a larger sample size, we choose the CPS since it is also used to measure official poverty in the USA. The CPS is sponsored by the US Census Bureau and the US Bureau of Labor Statistics. It is a nationally representative household survey and contains information, among others, on employment, education, health, income, demographic characteristics and so on. We include adults between 18 and 64 years old since the attributes such as employment status are more suitable to measure well-being among working age adults. ${ }^{11}$ The unweighted sample size varies from around 97,000 to 128,000 personal records; individual observations are weighted using ASEC weights. We estimate multiple poverty indices for the overall (working age) population as well as separately among individuals belonging to different

\footnotetext{
10 Dhongde and Haveman (2017) and Dhongde et al. (2019) use ACS data; Glassman (2019) also uses ACS but combines information from CPS. Mitra and Brucker (2019) is the only study which has used only CPS data.

11 Individuals who are full-time students or in the armed forces are not included.
}

racial/ethnic groups, namely Whites, Blacks, American Indians, Asians and Hispanics, and analyze how multidimensional poverty varied among these subgroups over the last decade.

\section{Attributes and thresholds}

The choice of dimensions reflects a normative decision in the design of any multidimensional poverty measure (Alkire et al. 2015). We follow previous literature on multidimensional poverty in the USA and select dimensions based on recommendations made by the Commission on the Measurement of Economic Performance and Social Progress (Stiglitz et al. 2009). ${ }^{12}$ The Commission's report recommends a range of objective features to be considered in any assessment of quality of life. These include health, education, personal activities, political voice and governance, social activities, environmental conditions, personal insecurity and economic insecurity. The CPS does not have data to measure deprivation in each of these dimensions. Instead, we use data on some indicators or attributes which capture some aspects of quality of life indicated by these dimensions. For example, a lack of health insurance as an attribute captures only part of what economic insecurity may mean for an individual. Table 2 lists the dimensions on which data is available in the CPS. For each of these five dimensions, we also list the

\footnotetext{
12 Dhongde and Haveman (2017), Dhongde et al. (2019), Glassman (2019), Mitra and Brucker (2019).
} 
Fig. 1 Percentage Deprived in Each Attribute over Time. Note: Authors' calculations using CPS-ASEC data. Vertical axis shows percentage values

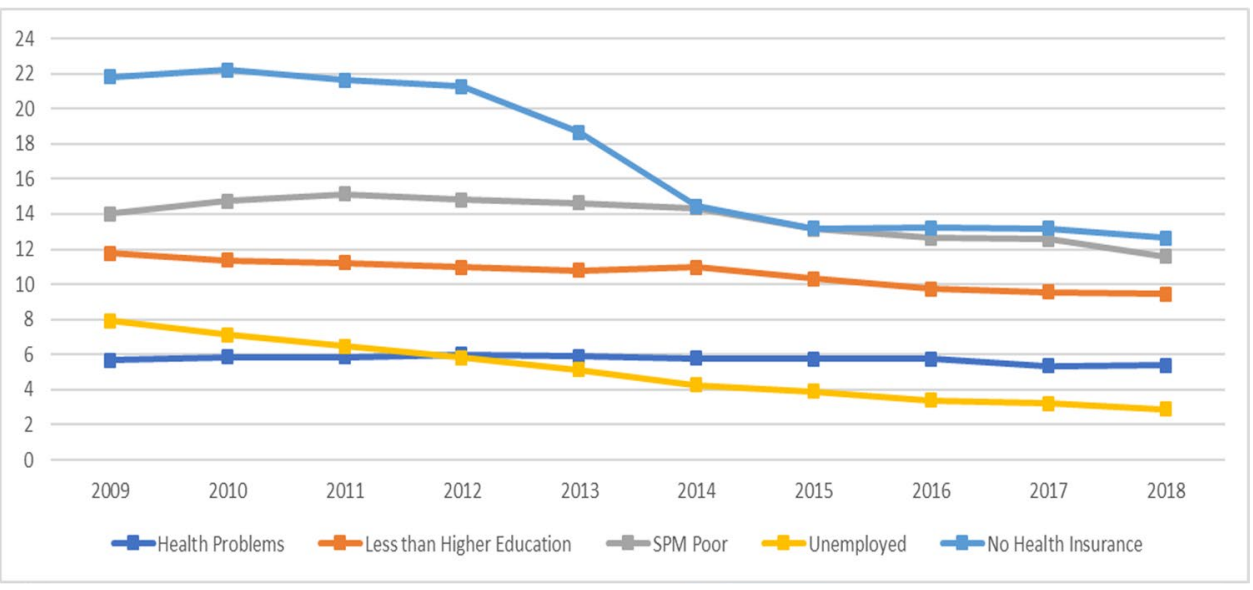

attribute used from the CPS data and the threshold used to identify deprivation in that attribute.

The CPS does not compile detailed data on health attributes. It asks individuals whether they have any one of the six disabilities: 1) self-care difficulty; 2) hearing difficulty; 3) vision difficulty; 4) ambulatory difficulty; 5) independent living difficulty; and 6) cognitive difficulty. In addition to data on disabilities, the CPS also has data on self-evaluated health status. Individuals report their health status as 'excellent,' 'very good,' 'good,' 'fair' or 'poor.' An individual is deprived in the health attribute if she reports poor health or she has two or more disabilities. ${ }^{13}$ Similarly, if an individual has less than high school educational attainment, she is considered as deprived of education. Standard of living is measured by comparing an individual's income level with the poverty threshold. An individual is considered deprived if she is identified as poor using the SPM poverty threshold. The fourth attribute identifies an individual as deprived if the individual is unemployed during the survey reference week. Finally, we measure economic security as having health insurance, private or public. An individual is deprived if she is not currently covered by any health insurance program.

\section{Deprivation in each attribute}

Figure 1 depicts the trend in deprivation in each attribute over the decade. A significant proportion of individuals (17.22\%) did not have any health insurance over the decade. The proportion of individuals without health insurance declined from $21.79 \%$ in 2009 to $12.65 \%$ in 2018 . Unemployment steadily decreased from $7.91 \%$ in 2009 at the peak of the Great Recession, to $2.89 \%$ in 2018 . The average proportion of people who lived below the SPM poverty threshold declined overtime and so did the proportion of people

\footnotetext{
13 Although we note that having multiple disabilities does not necessarily imply having poor health.
}

who had less than high school education. We calculate the correlations of deprivation among attributes (see Appendix Table 7) and find that the coefficients are low in value. This indicates that none of the attributes provides redundant information on individual's well-being.

There was significant variation in terms of deprivation in each attribute among racial and ethnic groups. In Fig. 2, we show the percentage of individuals deprived in each attribute by race and ethnicity averaged over time. Overall Hispanics, American Indians and Blacks had higher deprivation rates in each attribute than Whites and Asians. Asians were the least deprived in each of the five attributes. In the overall population, deprivation was high in health insurance. More than $30 \%$ of Hispanics and American Indians had no health insurance. SPM poverty levels were high among Blacks, Hispanics and American Indians with more than $20 \%$ who were income poor. On average, $10.62 \%$ of population did not have high school education. However, that proportion was significantly higher among Hispanics (29.92\%) and American Indians (21.08\%). Compared with overall unemployment levels of about $5 \%$ over the decade, Blacks (8.16\%), American Indians $(7.60 \%)$ and Hispanics $(6.07 \%)$ had greater unemployment levels.

\section{The Headcount ratio of Multidimensional Poverty}

Figures 1 and 2 show a dashboard of deprivation in each attribute over the last decade. In this section, we estimate the headcount ratio of multidimensional poverty, which gives the proportion of individuals who were deprived in at least two of the five attributes. ${ }^{14}$ Figure 3 shows the trends in the

\footnotetext{
14 Several previous research (Dhongde and Haveman 2017; Glassman 2019; Mitra and Brucker 2019; Dhongde et al. 2019) adopt the threshold of deprivation in at least two attributes to measure multidimensional poverty. We provide estimates of $\mathrm{H}$ using other thresholds and associated standard errors in Appendix Table 8.
} 
Fig. 2 Percentage Deprived in Each Attribute by Race/Ethnicity Averaged over Time. Note: Authors' calculations using CPS-ASEC data. Vertical axis shows percentage values
Fig. 3 Trends in the Headcount Ratio of Multidimensional Poverty by Race/Ethnicity. Note: Authors' calculations using CPS-ASEC data. Vertical axis shows percentage values

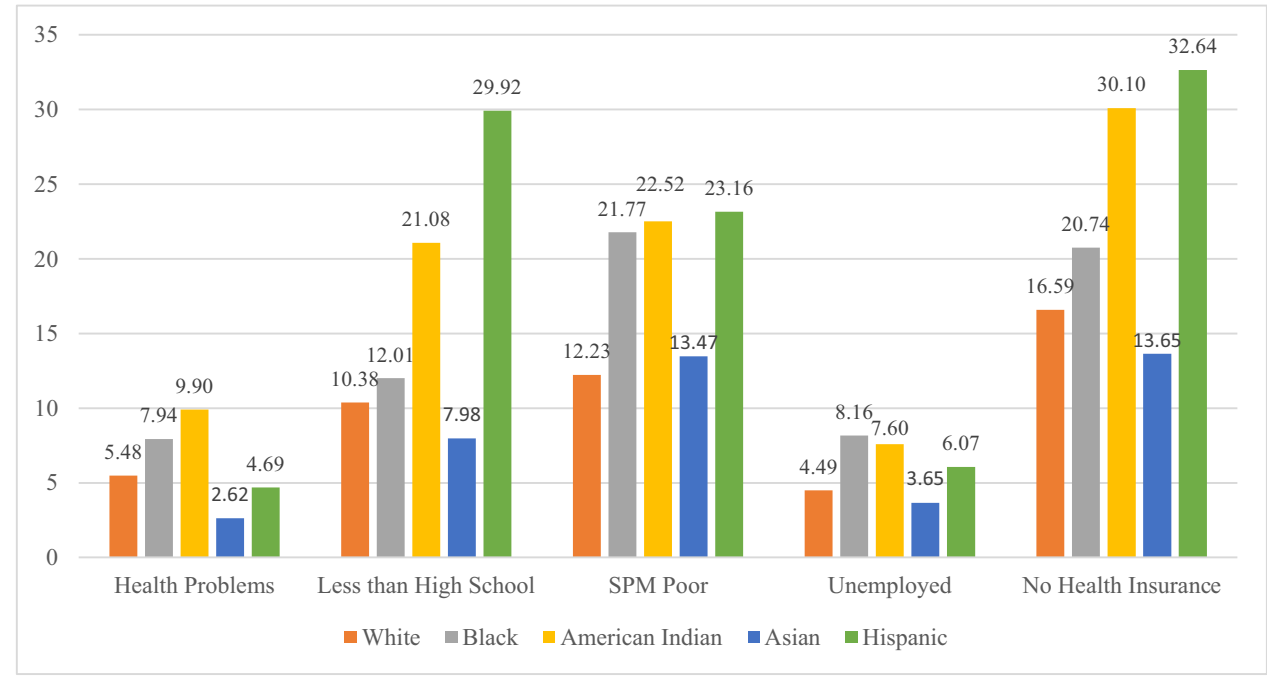

headcount ratio $\left(H=\frac{q}{n}\right)$ of multidimensional poverty for the overall population and for population subgroups by race/ethnicity. On average, about $13 \%$ of individuals were deprived in at least two attributes in the overall population. The multidimensional headcount ratio dropped from $16 \%$ at the peak of the recession in 2010 to less than $10 \%$ in 2018 . This result is consistent with estimates of Dhongde and Haveman (2017) based on the ACS data, with a peak at $15.5 \%$, in 2010, and with Mitra and Brucker (2019), who used the CPS data and found that the ratio declined to $10.0 \%$ in $2017 .{ }^{15}$

Compared with the overall population, Blacks, American Indians and Hispanics had much higher proportions of

\footnotetext{
15 Note that Mitra and Brucker (2019) includes children and older people (age 65 and over).
}

multidimensional poor. The trends in Fig. 3 show that the headcount ratio declined among all racial and ethnic groups. The headcount ratio among Hispanics declined from as high as $36.83 \%$ in 2009 to $21.15 \%$ in 2018 . Similarly, $32.04 \%$ of American Indians were multidimensional poor in 2010 and that proportion declined to $18.44 \%$ in 2018. Asians had least proportions of multidimensional poor (9.13\%) among all racial groups. Previous studies have found similarly high proportion of multidimensional poor among Blacks and Hispanics and lower proportion among Whites and Asians though there is much variation since these estimates are based on different datasets, different time periods, different attributes, etc. (see Table 9 in Appendix).

In order to understand why trends in the headcount ratio of multidimensional poverty varied across groups, we show in Fig. 4, average annual percentage change in the 
Fig. 4 Percentage Decline in Deprivation in Each Attribute by Race/Ethnicity Averaged Over Time. Note: Authors' calculations using CPS-ASEC data. Values show average of annual percentage change in the number of deprived in each indicator
Table 3 Estimates of Multidimensional Poverty using Alternative Indices

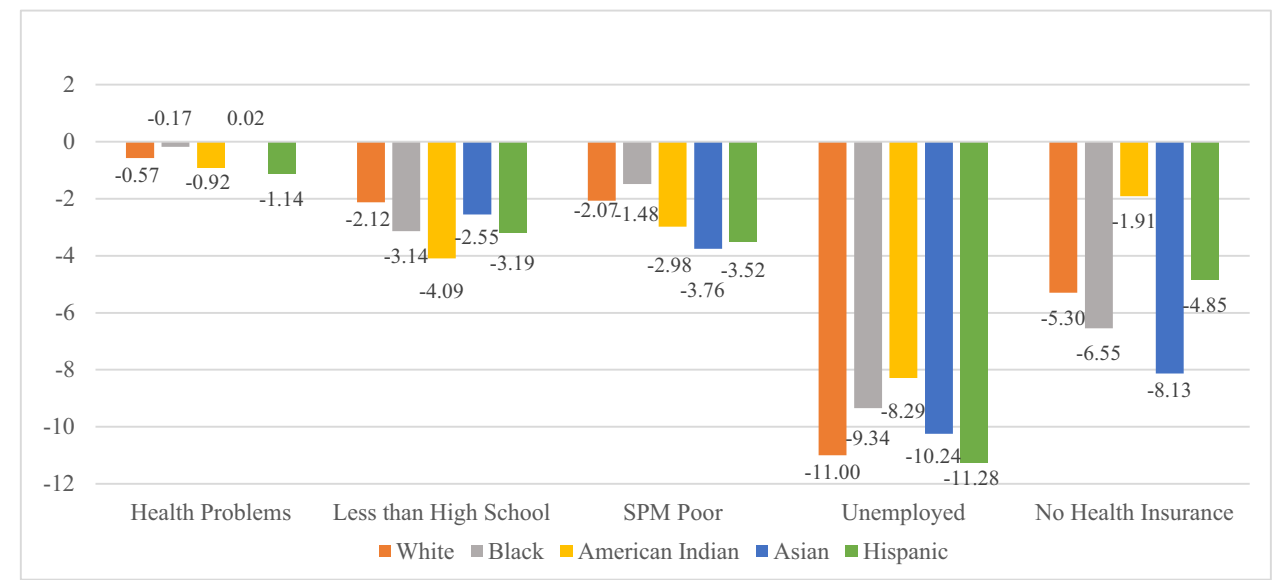

\begin{tabular}{lllllllllllll}
\hline & \multirow{2}{*}{ I. Recession } & \multicolumn{3}{l}{$\begin{array}{l}\text { II. Following } \\
\text { Recession }\end{array}$} & \multicolumn{3}{l}{$\begin{array}{l}\text { III. Short-Term } \\
\text { Recovery }\end{array}$} & \multicolumn{5}{c}{$\begin{array}{l}\text { III. Long-Term } \\
\text { Recovery }\end{array}$} \\
\hline Values & $\mathbf{2 0 0 9}$ & $\mathbf{2 0 1 0}$ & $\mathbf{2 0 1 1}$ & $\mathbf{2 0 1 2}$ & $\mathbf{2 0 1 3}$ & $\mathbf{2 0 1 4}$ & $\mathbf{2 0 1 5}$ & $\mathbf{2 0 1 6}$ & $\mathbf{2 0 1 7}$ & $\mathbf{2 0 1 8}$ & Average \\
P_AF & 0.122 & 0.123 & 0.121 & 0.118 & 0.110 & 0.100 & 0.093 & 0.089 & 0.088 & 0.084 & 0.105 \\
P_SY & 0.207 & 0.207 & 0.204 & 0.200 & 0.188 & 0.172 & 0.161 & 0.156 & 0.153 & 0.148 & 0.180 \\
P_DO & 0.046 & 0.046 & 0.045 & 0.044 & 0.039 & 0.034 & 0.031 & 0.030 & 0.029 & 0.028 & 0.037 \\
P_RP & 0.030 & 0.030 & 0.029 & 0.028 & 0.025 & 0.022 & 0.019 & 0.018 & 0.018 & 0.017 & 0.024 \\
Chg & & $\mathbf{2 0 1 0}$ & $\mathbf{2 0 1 1}$ & $\mathbf{2 0 1 2}$ & $\mathbf{2 0 1 3}$ & $\mathbf{2 0 1 4}$ & $\mathbf{2 0 1 5}$ & $\mathbf{2 0 1 6}$ & $\mathbf{2 0 1 7}$ & $\mathbf{2 0 1 8}$ & Average \\
P_AF & & 0.22 & -1.58 & -2.40 & -6.46 & -9.59 & -7.02 & -3.35 & -2.11 & -4.22 & -4.06 \\
P_SY & & 0.17 & -1.52 & -2.02 & -6.05 & -8.64 & -6.35 & -3.08 & -2.02 & -3.41 & -3.66 \\
P_DO & & 0.21 & -2.64 & -2.62 & -9.87 & -12.69 & -9.01 & -4.81 & -3.28 & -2.82 & -5.28 \\
P_RP & 0.24 & -3.13 & -2.70 & -11.54 & -14.33 & -9.89 & -5.65 & -3.80 & -2.06 & -5.87 \\
\hline
\end{tabular}

Authors' calculations using CPS-ASEC data. Poverty estimates in the table are rounded at 3 decimals, but the annual change is calculated using original values. Proportional change given in percentage proportion of individuals deprived in each attribute by race and ethnicity. There is significant variation in the way deprivation declined among these groups. Some of the largest declines were among the proportion of individuals deprived of employment and health insurance. Hispanics (-11.28\%) and Whites $(-11.00 \%)$ had a relatively greater reduction in deprivation in terms of unemployment, followed by Asians $(-10.24 \%)$ and Blacks (-9.34\%). On the other hand, Hispanics $(-4.85 \%)$ and American Indians (-1.91\%) experienced substantially lower decline in deprivation in terms of health insurance; recall that in Fig. 2 these two groups had higher percentage of individuals deprived of health insurance.

\section{Alternative Indices of Multidimensional Poverty}

The headcount ratio measures the incidence or the proportion of multidimensional poor. The poverty indices we discussed in "Alternative Multidimensional Poverty Indices" section measure both the poverty incidence and intensity. We use the union approach and identify individuals with at least one deprivation as multidimensionally poor. ${ }^{16}$ The $P_{A F}$ index measures the average score of deprivations shared by the entire population. It is insensitive to the inequality in the deprivation scores among the multidimensional poor. The $P_{S Y}$ index allocates more weight for individuals with higher deprivation scores to measure inequality among all individuals. We use $\mathrm{g}[S]=2 \mathrm{~S}-\mathrm{S}^{2}$ and $\mathrm{m}=1$ to estimate $P_{S Y}$, following Silber and Yalonetzky (2013). The $P_{D O}$ index satisfies deprivation decreasing switch, and we adopt the power function, $\mathrm{g}\left[\delta_{i}\right]=\delta_{i}{ }^{2}$ for $P_{D Q \dot{5}}$. For $P_{R P}$, we choose $\alpha=1.5$ and therefore, $\left(\delta_{i}\right)^{\alpha+1}=\left(\delta_{i}\right)^{2.5}$. In this case, as noted in Rippin (2016), attributes are assumed to be substitutes of each other. Recall that the $P_{R P}$ index uses a relative measure of inequality, which belongs to the class of generalized entropy indices. The index measures inequality in deprivation scores of individuals identified as poor.

\footnotetext{
16 The union approach leads to a greater proportion of individuals identified as poor, hence we used the intermediate approach (individuals with at least 2 out of 5 deprivations) to measure the headcount ratio of poverty and use the union approach to estimate indices other than the headcount ratio.
} 
Table 4 Multidimensional Poverty by Race/Ethnicity using Alternative Indices

\begin{tabular}{|c|c|c|c|c|c|c|c|c|c|c|c|}
\hline & \multicolumn{5}{|c|}{$\begin{array}{l}\text { Alternative Multidimensional } \\
\text { Poverty Indices }\end{array}$} & \multicolumn{6}{|c|}{ Proportion of Poor } \\
\hline & $P \_A F$ & $P \_S Y$ & $P_{-} D O$ & $P \_R P$ & Rank & $\begin{array}{l}\mathrm{H} \\
\text { Multid }\end{array}$ & Rank & $\begin{array}{l}\text { SPM } \\
\text { Income }\end{array}$ & Rank & $\begin{array}{l}\text { OPM } \\
\text { Income }\end{array}$ & Rank \\
\hline Hispanic & 0.193 & 0.295 & 0.076 & 0.051 & 1 & 28.36 & 1 & 23.16 & 1 & 19.0 & 2 \\
\hline American Indian & 0.182 & 0.280 & 0.071 & 0.047 & 2 & 25.69 & 2 & 22.52 & 2 & N/A & - \\
\hline Black & 0.141 & 0.227 & 0.052 & 0.034 & 3 & 18.46 & 3 & 21.77 & 3 & 21.6 & 1 \\
\hline White & 0.098 & 0.168 & 0.035 & 0.022 & 4 & 11.98 & 4 & 12.23 & 5 & 11.1 & 3 \\
\hline Asian & 0.084 & 0.146 & 0.027 & 0.015 & 5 & 9.13 & 5 & 13.47 & 4 & 10.6 & 4 \\
\hline
\end{tabular}

All values averaged over ten years. Estimates of alternative indices, proportion of multidimensional poor (H) and SPM poor are based on authors' calculations using CPS-ASEC data. Proportion of OPM poor based on Census estimates using ASEC CPS data (https://www2.census.gov/programs-surveys/demo/ tables/p60/273/tableB-5.xls)
The top panel of Table 3 shows the estimates of each of the four indicators for the 10 years, and the bottom panel shows the average annual change in these values. Over the decade, the average values of indices $P_{A F}$ and $P_{S Y}$ were equal to 0.105 and 0.180 , respectively; the average values of $P_{D O}$ and $P_{R P}$ were 0.037 and 0.024 , respectively. The smaller values in the later set of indices are explained by the fact that both Dhongde et al. (2016) and Rippin (2016) use convex functions to aggregate individual's deprivation. Regardless of the index used we find that multidimensional poverty steadily declined over the last decade. The annual average decline in multidimensional poverty was in the range of $3.66 \%\left(P_{S Y}\right)$ to $5.87 \%\left(P_{R P}\right)$.

The decade long decline in multidimensional poverty can be roughly divided into four stages. During the Great Recession (2009-2010), multidimensional poverty increased regardless of the indices used to measure it. In the years, immediately following the recession, between 2010 and 2012 poverty levels declined slowly. The average annual decline was $4 \%$ or less in all the indices. However, from 2013 to 2015 , multidimensional poverty declined rapidly, almost at or above $10 \%$ per year, in $P_{D O}$ and $P_{R P}$. The rapid recovery rate between 2013 and 2015 was partly due to the implementation of the Affordable Care Act (ACA), which led to a significant decrease in the proportion of individuals without health insurance (see Fig. 1). Since 2016, we find that the pace of decline in multidimensional poverty gradually slowed down. The slower rate since 2016 can be partly explained by the expiration of the American Recovery and Reinvestment Act in 2015. Unemployment rates declined more gradually since 2015 than in previous years and so did the SPM poverty levels (see Fig. 1). Additionally, the ACA was not fully implemented by all states and as a result, the proportion of individuals deprived of health insurance increased slightly between 2015 and 2016 .

Table 10 in Appendix provides estimates of each of the four indices for each year by race and ethnicity. We see similar trends among these subgroups; multidimensional poverty increased during the recession-less so among Whites and more so among Hispanics and then tended to decline between 2013 and 2018. Asians not only had some of the lowest values of poverty indices but also experienced greatest decline in multidimensional poverty (annual average decline of about $5 \%$ ). The values in Table 10 are averaged over time and summarized in Table 4 . We find that although these indices assess multidimensional poverty in different ways, they all provide consistent ranking. Hispanics suffered the highest multidimensional poverty, followed by American Indians, Blacks and Whites. Asians had the least multidimensional poverty when measured by any of the four indices. We compare this ranking with the headcount ratio of multidimensional poverty (also shown in Fig. 3) and the headcount ratio of income poverty, using both SPM and OPM thresholds. We find that the ranking by the alternative indices is consistent with the ranking by these headcount ratios. Thus, the incidence of income poverty and the incidence, inequality and severity of multidimensional poverty were consistently high among Hispanics, followed by American Indians, Blacks, Whites and Asians.

Note that out of the four indices, $P_{A F}$ and $P_{R P}$ are also subgroup decomposable, that is, the overall poverty index is equal to the weighted average of subgroup poverty levels, where weights are subgroup population shares. Similarly, the headcount ratio of poverty is also subgroup decomposable. In Table 5, we show decomposition of these indices by racial/ethnic groups; values are averaged over the 10-year period. We find that each subgroups' contribution to multidimensional poverty is consistent across the three indices. If we compare the contribution to poverty with population share, then Whites had a slightly lower share in poverty. Whites comprised of $78 \%$ of the population and $72 \%$ of the poor population. On the other hand, Blacks had a lower share in population (13\%) but a greater share in poverty (18\%). In particular, Hispanics had a much higher share in poverty (31\%-37\%) compared to their share in population (17\%). 
Table 5 Decomposition of Multidimensional Poverty by Race/Ethnicity using Alternative Indices

\begin{tabular}{lccrr}
\hline & $\begin{array}{l}\text { Population } \\
\text { Share \% }\end{array}$ & $\begin{array}{l}\text { Headcount } \\
\text { Contr. \% }\end{array}$ & $\begin{array}{l}\text { P_AF } \\
\text { Contr. \% }\end{array}$ & $\begin{array}{l}\text { P_RP } \\
\text { Contr. \% }\end{array}$ \\
\hline White & 77.93 & 72.51 & 73.22 & 72.30 \\
Black & 12.96 & 18.51 & 17.44 & 18.52 \\
American Indian & 1.14 & 2.29 & 1.99 & 2.28 \\
Asian & 5.84 & 4.02 & 4.64 & 3.68 \\
Other & 2.12 & 2.68 & 2.70 & 3.22 \\
Overall & 100.00 & 100.00 & 100.00 & 100.00 \\
Hispanic & 17.09 & 37.44 & 31.31 & 36.64 \\
Non-Hispanic & 82.91 & 62.56 & 68.69 & 63.36 \\
Overall & 100.00 & 100.00 & 100.00 & 100.00 \\
\hline
\end{tabular}

Authors' calculations using CPS-ASEC data. Values are averaged over 10 years

\section{Conclusions}

In this paper, we reviewed some of the recent developments in the formulation of multidimensional poverty indices. This is a valuable exercise in itself, for scholars who wish to understand the similarities and differences between different indices and estimate them empirically. Often, applied researchers shy away from using multiple indices, largely because it is difficult to comprehend the formulation of these indices. We provided numerical examples in the paper to illustrate how to use these different indices and discussed their advantages and limitations.

Recent literature on multidimensional poverty in the USA has almost exclusively relied on the Alkire and Foster (2011) set of indices. This paper filled the gap in the literature by estimating three alternative indices which improve upon the Alkire and Foster (2011) indices. Estimates of alternative indices provided a more complete picture of multidimensional poverty in the USA. We urge future researchers to follow suit and use different indices while estimating multidimensional poverty since every index captures different aspects (incidence, severity, inequality) of multidimensional poverty.

We used these alternative indices to analyze trends in multidimensional poverty by racial and ethnic groups. Our results indicate that in the past 10 years, multidimensional poverty in the USA decreased and the decline was consistently seen regardless of the poverty measure used. Of the five well-being attributes that we included in our analysis, we found that a large proportion of multidimensional poor were deprived of health insurance. Despite implementation of the Affordable Care Act, more than $30 \%$ of Hispanics and American Indians had no health insurance. Policies providing greater insurance coverage among American Indians and Hispanics may lead to lower multidimensional poverty among these groups. An equally high proportion of Hispanics were also deprived of high school education. Since the Great Recession, there has been a decline in overall income poverty rates, yet more than $20 \%$ of individuals were income poor among Blacks, Hispanics and American Indians. Asians not only had low proportions of multidimensional poor but also had some of the largest declines in multidimensional poverty between 2009 and 2018. Overall not only were a greater proportion of Hispanics identified as multidimensional poor, but we also found that they experienced greater intensity and severity of multidimensional poverty.

In the future, our analysis can be extended in several ways. Our choice of attributes was constrained by the availability of data in the CPS. We did not consider alternative thresholds for these attributes and alternative weights which may be attached to these attributes. Each of these exercises will shed important light on how the quality of life varies over time and across different demographics. With the ongoing Covid-19 pandemic and the resulting economic slowdown, we believe that differences in multidimensional poverty among different racial/ethnic groups in the USA will only increase further.

\section{Appendix}

Table 6 Axiomatic Properties of Alternative Multidimensional Poverty Indices

\begin{tabular}{lllll}
\hline Axioms & $P_{A F}$ & $P_{S Y}$ & $P_{D O}$ & $P_{R P}$ \\
\hline Non-Distributional Axioms: & & & & \\
i) Normalization & $\sqrt{ }$ & $\sqrt{ }$ & $\sqrt{ }$ & $\sqrt{ }$ \\
ii) Anonymity & $\sqrt{ }$ & $\sqrt{ }$ & $\sqrt{ }$ & $\sqrt{ }$ \\
iii) Monotonicity & $\sqrt{ }$ & $\sqrt{ }$ & $\sqrt{ }$ & $\sqrt{ }$ \\
iv) Strong Focus & $\sqrt{ }$ & $\sqrt{ }$ & $\sqrt{ }$ & $\sqrt{ }$ \\
v) Independence & $\sqrt{ }$ & $\sqrt{ }$ & $\sqrt{ }$ & $\sqrt{ }$ \\
vi) Principle of Population & $\sqrt{ }$ & $\sqrt{ }$ & $\sqrt{ }$ & $\sqrt{ }$ \\
vii) Subgroup Decomposability & $\sqrt{ }$ & $\times$ & $\times$ & $\sqrt{ }$ \\
viii) Factor Decomposability & $\sqrt{ }$ & $\times$ & $\times$ & $\sqrt{ }$ \\
Distributional Axioms: & & & & \\
ix) Correlation-Sensitive & $\times$ & $\times$ & $\sqrt{ }$ & $\sqrt{ }$ \\
x) Clustered Dimensional Deteriora- & $\times$ & $\times$ & $\sqrt{ }$ & $\times$ \\
tions and Deprivation & & & & \\
\hline
\end{tabular}

See Alkire and Foster (2011), Dhongde et. al. (2016) and Rippin (2016) for definitions of properties 
Table 7 Correlation

Coefficients of Deprivation in Different Attributes

\section{Health Problems}

Less than

High School

SPM Poor Unemployed

No Health

Insurance

Health Problems

1

Less than High School

SPM Poor

0.251

0.325

$-0.054$

$-0.031$

1

0.384

0.131

1

No Health Insurance

0.370

.227

0.302

Authors' calculations using CPS-ASEC data in 2019; coefficients for other years are available from the authors. Values list tetrachoric correlation coefficients used for binary data 


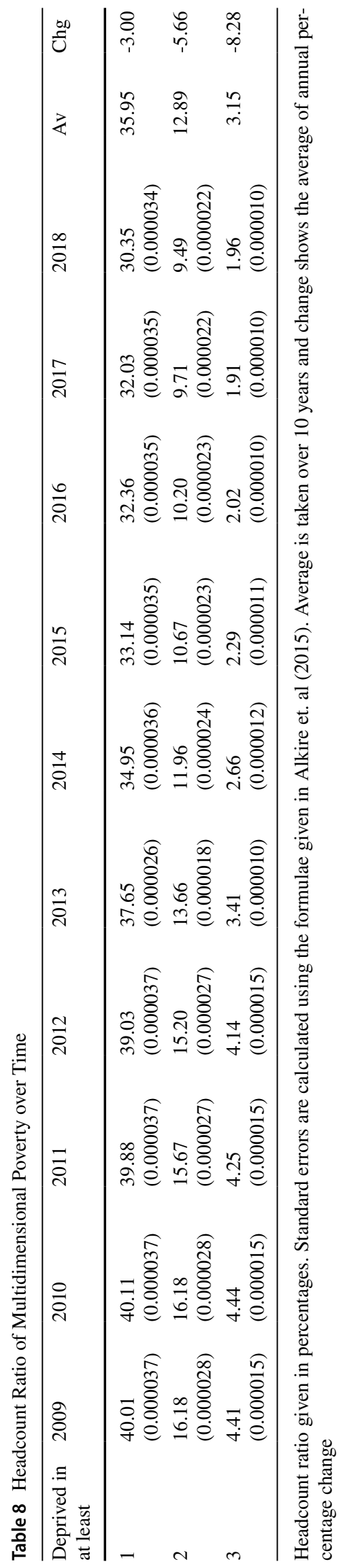


Table 9 Estimates of Multidimensional Poverty by Race and Ethnicity from Previous Literature

\begin{tabular}{|c|c|c|c|c|c|c|}
\hline Previous Research & Years & Whites (\%) & Blacks (\%) & $\begin{array}{l}\text { American Indi- } \\
\text { ans (\%) }\end{array}$ & Asians (\%) & Hispanics (\%) \\
\hline Alkire, S., \& Foster, J. (2011) & 2004 & 9.0 & 21.0 & N/A & N/A & 39.0 \\
\hline Mitra and Brucker (2016) & 2012 & 39.6 & 19.9 & N/A & 4.0 & 35.0 \\
\hline Dhongde and Haveman (2017) & $2008-2013$ & 11.9 & 17.7 & N/A & 19.6 & 40.5 \\
\hline Glassman (2019) & 2017 & 12.6 & 26.2 & 25.9 & 13.8 & 24.1 \\
\hline Mitra and Brucker (2019) & 2013-2017 & 10.6 & 17.7 & N/A & 8.1 & 23.3 \\
\hline White, R. (2020) & $2008-2018$ & 6.5 & 10.7 & 14.6 & 9.2 & 19.3 \\
\hline Dhongde (2020) & April 2020 & 20.5 & 29.1 & N/A & N/A & 37.2 \\
\hline This paper & 2009-2018 & 12.0 & 18.5 & 25.7 & 9.1 & 28.4 \\
\hline
\end{tabular}

Estimates show proportion of multidimensional poor deprived in two or more attributes; these are NOT strictly comparable as they are based on different datasets, different indicators and thresholds

Table 10 Trends in

Multidimensional Poverty using Alternative Indices by Racial/ Ethnic Groups

\begin{tabular}{|c|c|c|c|c|c|c|c|c|c|c|c|c|}
\hline \multirow[t]{2}{*}{ Stages } & \multicolumn{2}{|c|}{ I. Recession } & \multicolumn{2}{|c|}{$\begin{array}{l}\text { II. Following } \\
\text { Recession }\end{array}$} & \multicolumn{3}{|c|}{$\begin{array}{l}\text { III. Short-Term } \\
\text { Recovery }\end{array}$} & \multicolumn{3}{|c|}{$\begin{array}{l}\text { III. Long-Term } \\
\text { Recovery }\end{array}$} & \multirow[b]{2}{*}{ Av } & \multirow[b]{2}{*}{ Chg } \\
\hline & 2009 & 2010 & 2011 & 2012 & 2013 & 2014 & 2015 & 2016 & 2017 & 2018 & & \\
\hline \multicolumn{13}{|l|}{$P_{-} A F$} \\
\hline White & 0.115 & 0.114 & 0.113 & 0.110 & 0.103 & 0.095 & 0.087 & 0.085 & 0.083 & 0.079 & 0.098 & -4.05 \\
\hline Black & 0.165 & 0.169 & 0.163 & 0.163 & 0.149 & 0.129 & 0.128 & 0.120 & 0.116 & 0.111 & 0.141 & -4.20 \\
\hline American Indian & 0.208 & 0.209 & 0.212 & 0.211 & 0.196 & 0.172 & 0.158 & 0.155 & 0.153 & 0.150 & 0.182 & -3.47 \\
\hline Asian & 0.106 & 0.109 & 0.106 & 0.094 & 0.089 & 0.077 & 0.071 & 0.064 & 0.067 & 0.061 & 0.084 & -5.77 \\
\hline Hispanic & 0.235 & 0.229 & 0.227 & 0.219 & 0.203 & 0.185 & 0.164 & 0.157 & 0.153 & 0.156 & 0.193 & -4.37 \\
\hline \multicolumn{13}{|l|}{$P_{-} S Y$} \\
\hline White & 0.194 & 0.193 & 0.190 & 0.186 & 0.175 & 0.162 & 0.150 & 0.147 & 0.143 & 0.139 & 0.168 & -3.64 \\
\hline Black & 0.259 & 0.265 & 0.256 & 0.258 & 0.239 & 0.210 & 0.207 & 0.196 & 0.191 & 0.185 & 0.227 & -3.59 \\
\hline American Indian & 0.318 & 0.311 & 0.318 & 0.317 & 0.293 & 0.267 & 0.246 & 0.244 & 0.242 & 0.238 & 0.280 & -3.09 \\
\hline Asian & 0.179 & 0.184 & 0.179 & 0.163 & 0.154 & 0.134 & 0.125 & 0.114 & 0.119 & 0.111 & 0.146 & -5.02 \\
\hline Hispanic & 0.349 & 0.342 & 0.338 & 0.328 & 0.306 & 0.285 & 0.258 & 0.250 & 0.244 & 0.248 & 0.295 & -3.68 \\
\hline \multicolumn{13}{|l|}{ P_DO } \\
\hline White & 0.043 & 0.043 & 0.042 & 0.040 & 0.036 & 0.0 & 0.029 & 0.028 & 0.027 & 0.026 & 0.035 & -5.37 \\
\hline Black & 0.064 & 0.065 & 0.063 & 0.063 & 0.056 & 0.045 & 0.046 & 0.041 & 0.039 & 0.038 & 0.052 & -5.37 \\
\hline American Indian & 0.087 & 0.082 & 0.085 & 0.088 & 0.075 & 0.066 & 0.057 & 0.056 & 0.056 & 0.053 & 0.071 & -5.12 \\
\hline Asian & 0.035 & 0.037 & 0.036 & 0.032 & 0.029 & 0.024 & 0.022 & 0.019 & 0.020 & 0.019 & 0.027 & -6.27 \\
\hline Hispanic & 0.101 & 0.097 & 0.095 & 0.090 & 0.081 & 0.071 & 0.060 & 0.057 & 0.055 & 0.057 & 0.076 & -6.00 \\
\hline \multicolumn{13}{|l|}{$P \_R P$} \\
\hline White & 0.028 & 0.028 & 0.027 & 0.026 & 0.023 & 0.020 & 0.018 & 0.017 & 0.016 & 0.016 & 0.022 & -5.92 \\
\hline Black & 0.043 & 0.043 & 0.041 & 0.042 & 0.037 & 0.029 & 0.029 & 0.026 & 0.024 & 0.024 & 0.034 & -5.98 \\
\hline American Indian & 0.060 & 0.055 & 0.058 & 0.061 & 0.050 & 0.044 & 0.036 & 0.036 & 0.036 & 0.034 & 0.047 & -5.72 \\
\hline Asian & 0.022 & 0.023 & 0.022 & 0.020 & 0.018 & 0.014 & 0.013 & 0.011 & 0.012 & 0.011 & 0.017 & -6.99 \\
\hline Hispanic & 0.070 & 0.067 & 0.065 & 0.062 & 0.054 & 0.047 & 0.039 & 0.037 & 0.035 & 0.036 & 0.051 & -6.94 \\
\hline
\end{tabular}

Authors' calculations using CPS-ASEC data. The multidimensional poverty estimates are calculated using the union approach, that is, people are deprived in at least one indicator. Average is taken over 10 years and change shows the average of annual percentage change 
Data Availability Statement The data analyzed during the current study are publicly available in the IPUMS data repository: https://usa.ipums. org/usa/

\section{Declarations}

Conflict of Interest Statement The authors wish to declare that there is no conflict of interest involved.

-Shatakshee Dhongde.

-Xiaoyu Dong.

\section{References}

Aaberge R, Brandolini A. Multidimensional poverty and inequality. In Handbook of Income Distribution Elsevier. 2015;2(C3):141-216.

Alkire S, Foster J. Counting and multidimensional poverty measurement. J Public Econ. 2011;95(7-8):476-87.

Alkire S, Foster JE, Seth S, Santos ME, Roche JM, Ballon P. Multidimensional poverty measurement and analysis, Oxford: Oxford University Press, Chapter 3. OPHI Working Paper No. 84; 2015.

Alkire S, Seth S. Multidimensional Poverty Reduction in India between 1999 and 2006: Where and how? World Dev, Elsevier. 2015;72(C):93-108.

Aguilar GR, Sumner A. Who are the world's poor? A new profile of global multidimensional poverty. World Dev. 2020;126.

Atkinson A. Multidimensional deprivation: contrasting social welfare and counting approaches. J Econ Inequal. 2003;1:51-65.

Battiston D, Cruces G, Lopez-Calva LF, Lugo MA, Santos ME. Income and beyond: Multidimensional poverty in six Latin American Countries. Soc Indic Res. 2013;112(2):291-314.

Berenger V. Using ordinal variables to measure multidimensional poverty in Egypt and Jordan. J Econ Inequal. 2017;15(2):143-73.

Berenger V. The counting approach to multidimensional poverty. The case of four African countries. S Afr J Econ. 2019;87:200-27.

Bourguignon F, Chakravarty SR. The measurement of multidimensional poverty. J Econ Inequal. 2003;1:25-49.

Dhongde, S. (2020). Multidimensional economic deprivation during the coronavirus pandemic: Early evidence from the United States. PloS One, 15(12), e0244130.

Dhongde S, Haveman R. Multi-dimensional deprivation in the U.S. Soc Indic Res. 2017;133(2):477-500.

Dhongde S, Li Y, Pattanaik P, Xu Y. Binary Data, Hierarchy of attributes, and multidimensional deprivation. J Econ Inequal. 2016;14(4):363-78.

Dhongde S, Pattanaik P, Xu Y. Well-being, deprivation, and the great recession in the U.S.: A study in a multidimensional framework. Rev Income Wealth. 2019;65:281-306.
Dotter C, Klasen S. The multidimensional poverty index: Achievements, conceptual and empirical issues. Discussion Papers. No. $233 ; 2017$.

Flood S, King M, Rodgers R, Ruggles S, Warren J, Westberry M. Integrated Public Use Microdata Series, Current Population Survey: Version 9.0. Minneapolis, MN: IPUMS; 2021.

Foster J, Greer J, Thorbecke E. A Class of Decomposable Poverty Measures. Econometrica. 1984;52(3):761-6.

Glassman B. Multidimensional deprivation in the United States: 2017. American Community Survey Reports, ACS-40. Washington, D.C.: US Census Bureau; 2019.

Garner T, Gudrais M. Alternative Poverty Measurement for the U.S.: Focus on Supplemental Poverty Measure Thresholds. Bureau of Labor Statistics Working Papers 510; 2018.

Mitra S, Brucker D. Income Poverty and Multiple Deprivations in a High- Income Country: The Case of the United States. Soc Sci Q. 2016;98(1):37-56.

Mitra S, Brucker D. Monitoring multidimensional poverty in the United States. Econ Bull. 2019;39(2):1272-93.

Pattanaik P, Xu Y. On measuring multidimensional deprivation. J Econ Lit. 2018;56(2):657-72.

Rippin N. Multidimensional poverty in Germany: A capability approach. Forum Soc Econ. 2016;45(2-3):230-55.

Santos ME, Villatoro P. A multidimensional poverty index for Latin America. Rev Income Wealth. 2018;64:52-82.

Silber J, Yalonetzky G. Measuring multidimensional deprivation with dichotomized and ordinal variables. In: Betti G, Lemmi A, editors. Poverty and Social Exclusion: New Methods of Analysis. Routledge Frontiers of Political Economy. London and New York: Routledge; 2013.

Sen A. Conceptualizing and measuring poverty. In: Grusky D, Kanbur R, editors. Poverty and Inequality. Palo Alto: Stanford University Press; 2006.

Stiglitz JE, Sen A, Fitoussi JP. Report by the Commission on the Measurement of Economic Performance and Social Progress; 2009.

Whelan CT, Nolan B, Maitre B. Multidimensional poverty measurement in Europe: An application of the adjusted headcount approach. J Eur Soc Policy. 2014;24(2):183-97.

White R. Variation in Multidimensional Poverty Across Socio-Demographic Cohorts. In Multidimensional Poverty in America. The Incidence and Intensity of Deprivation, 2008-2018. Cham: Palgrave Macmillan; 2020.

Publisher's Note Springer Nature remains neutral with regard to jurisdictional claims in published maps and institutional affiliations. 